\title{
A new approach to the design of preschool institutions
}

\author{
Tatiana V. Filanova ${ }^{1}$, Mikhail Yu. Zhuravlev ${ }^{1}$, Ekaterina A. Mikhaylova ${ }^{1, *}$ \\ ${ }^{1}$ Samara State Technical University, Molodogvardeyskaya st., 224, Samara, Samarskaya obl., 443001, \\ Russia
}

\begin{abstract}
The paper considers a new approach to the design of preschool institutions, taking into account the psychology of children's perception. The basic principles of creating the environment, motivating children to study, developing their mental, creative and physical abilities were identified. Buildings of preschool institutions are seen as means of the world perception and social adaptation of children. The child perceives the world through visual, tactile and other sensations. All factors of changing world should be reflected in the architectural style of a building. The paper defines principles of designing preschool institutions based on numerous studies of architects and psychologists: it is proposed to create projects for children, which will function as "giant space for games" with an open plan, and child-sized friendly corners as well. It is necessary to provide visual variety of forms, to use playful elements as a part of the façade, to convert the walking paths into the playground, and also to use the ecological approach in the design.
\end{abstract}

\section{Introduction}

Currently the design of preschool institutions is aimed at creating the environment, which develops mental, physical and creative abilities of a child, who perceives the world through visual, tactile and other sensations, and all factors of the changing world should be reflected in the architectural style of a building. This article identifies and studies the basic principles of creating such a developing environment which have been used in Europe for many years. For Russia these principles are innovative and should be universally implemented in practice while creating projects for children.

\section{The study of the main tendencies in the design of preschool institutions}

Historical analysis of the design of institutions for children has shown the origin of such projects. Preschool institutions as a building type first appeared in Germany in the early nineteenth century, the creator of this concept was Friedrich Fröbel, a German theorist. In the late XIX century Rudolf Steiner, the Austrian philosopher and architect, revealed the impact of architectural environment on the psychological state of a child.

\footnotetext{
*Corresponding author: arch_katherine@rambler.ru
} 


\subsection{Four approaches of designing kindergartens in the 1980-ies}

In the mid-twentieth century preschool institutions in Europe were not particularly attractive as far as the architectural look is concerned, only the functional point was considered in their design. In the 1980-ies it was realized that preschool institutions are a completely new building type, requiring a special approach to their design. At the same period four main approaches of preschool institutions design were developed (figure 1) [1].

The first approach is metaphorical. An illustrative example is the kindergarten project "KITA" in Frankfurt. Architect Christoph Mackler believed that there was no such thing as architecture for children. In his project there are no so-called "children's elements". He used the metaphor of a small town where classes are a kind of terraced housing, and the corridor plays the role of a street. Critics believed that Mackler was too serious about children, and that the environment was too detached from reality in his project.

Another example of the metaphor approach is the kindergarten in the form of a sinking ship in Stuttgart (Luginsland Kindergarten, Stuttgart by architects Behnisch and Partner architects) (Fig. 1A).

The second approach is organic. In his kindergarten project Austrian architect Hundertwasser attempted to establish a link between a man and nature by means of architecture (Fig. 1b).

The third approach includes the structures of late modern. According to architects, developing this approach, a building is only a frame, a neutral shell without any narrative content, and the elements relevant to children, should be placed inside this frame. The example is the kindergarten by architect Wilson (Fig. 1c).

The fourth approach is the modular architecture. The examples are temporary structures assembled from the factory blocks to meet social needs in the postwar period (Fig. 1d) [2].

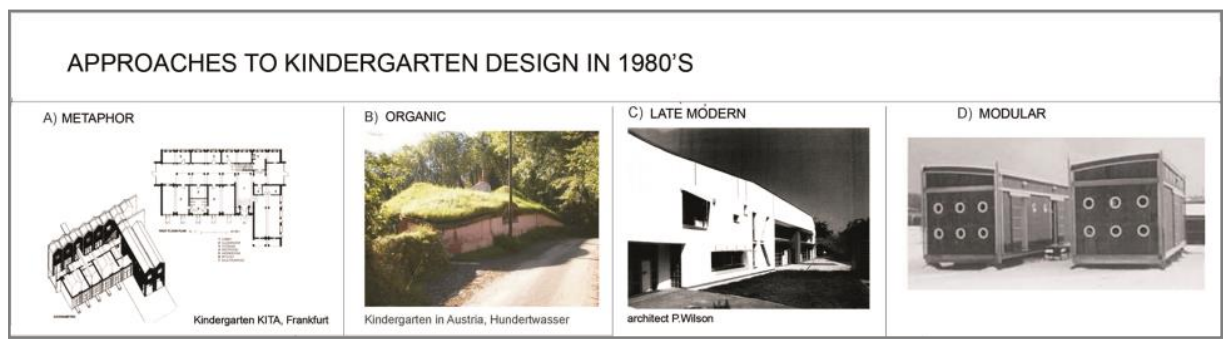

Fig. 1. The basic approaches in the design of preschool institutions in the 1980-ies.

\section{Principles of preschool institutions design based on the research of psychologists}

Today, architects around the world are also concerned with the question of what a modern preschool institution should be. At the end of the XX century the studies in the field of the children's psychology were being actively conducted, and they all were reflected in this or that way in the modern architecture of kindergartens (Fig. 2-4).

\subsection{Design principles based on studies of psychologists}

According to the research by Judith Seaver "The Philosophy of the Educational Approach", interior design must be directly connected with educational program, which includes structured activities (scheduled classes) and unstructured activities (allowing a child to choose classes) [1]. With that in mind, the main tendency in designing modern preschool 
institutions should be "open structure" room layout and throwing out the traditional corridor system. In large spaces the zones for both quiet relaxation and active games are created with the help of movable partitions, different floor levels, different floor coverings and other ways. Children, following their inner impulses, choose themselves what they want to do. Thus, a flowing space without "idle" places is formed (Fig. 2a) [3].

In 1994, one more study-experiment was conducted: inside the standard classroom another smaller "classroom" in the form of a box structure was created. When in a smaller room, children were spending much more time on a specific activity, than in standard classroom [1]. It was concluded that in the structure of the building, the architects should provide more private, reduced-scaled spaces for children. One of the examples of such solution of the kindergarten design with open plan and private spaces is the kindergarten in Tromso in Norway (Fig. 2b) [4].

Psychologists came to one more conclusion that architects must keep in mind visual horizons of the child: windows at the child's eye level, horizontal elements corresponding to the door height (Fig. 2c) [1,5].

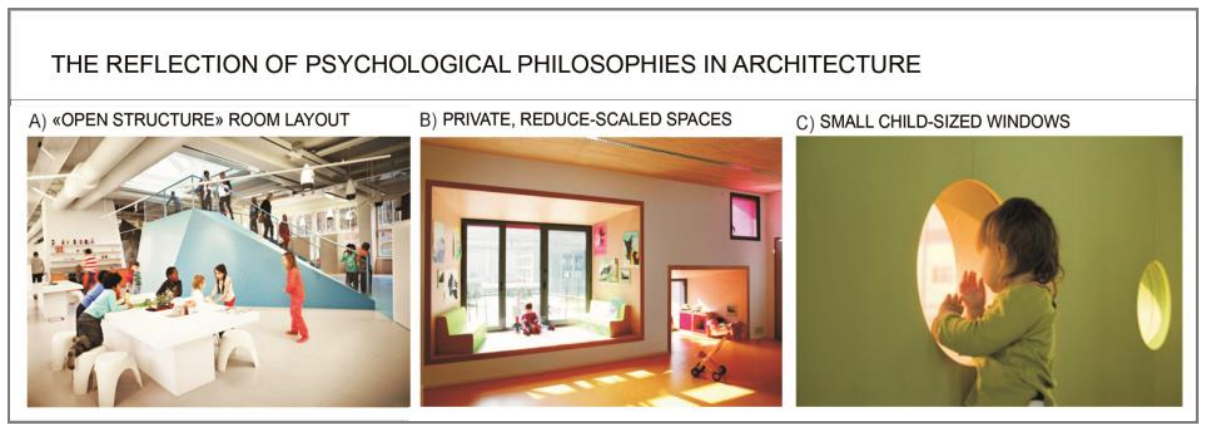

Fig. 2. Design principles based on the research of psychologists.

\subsection{Psychological research of the contrasts}

In 2000 Anita Rui Olds in her research discovered that the environment had a positive influence on the development of infants, and should have the contrasts created by the architect. Inside-outside, high-low, light-dark, emptiness-filled space, succession-mystery, contrast between order and chaos, simple and abstract forms - all these contrasts create a variety of room shapes, colors, lighting. (Fig. 3) [6].

The example of how contrasts and various rooms in the building are formed due to the irregular shape of the building, which can be both streamlined and acute-angled, are Fageborg Kindergarten by RRA, 2003 and Tellus Nursery School, 2010 (educational institutions for children) (Fig. 3a) [7].

There are a lot of examples where, on the contrary, the general layout solution is simple, and the contrasts are formed by the colors. Color is often used to help children to orientate in the structure of the building, that's why the walking paths - the entrance area, corridors and communications are highlighted by color (Fig. 3b).

The kindergarten "House of light" in Japan is an example of creating different moods in the classroom due to color and light. Light wells have different orientation and the image of the room changes during the day due to the position of the sun (Fig. 3c) [8].

The theme of contrasts between simple and abstract forms, order and chaos, flowing and angled shapes is revealed in the building of the day-care centre in New York city. The form of the building gives children a completely different experience (Fig. 3d) [1]. 


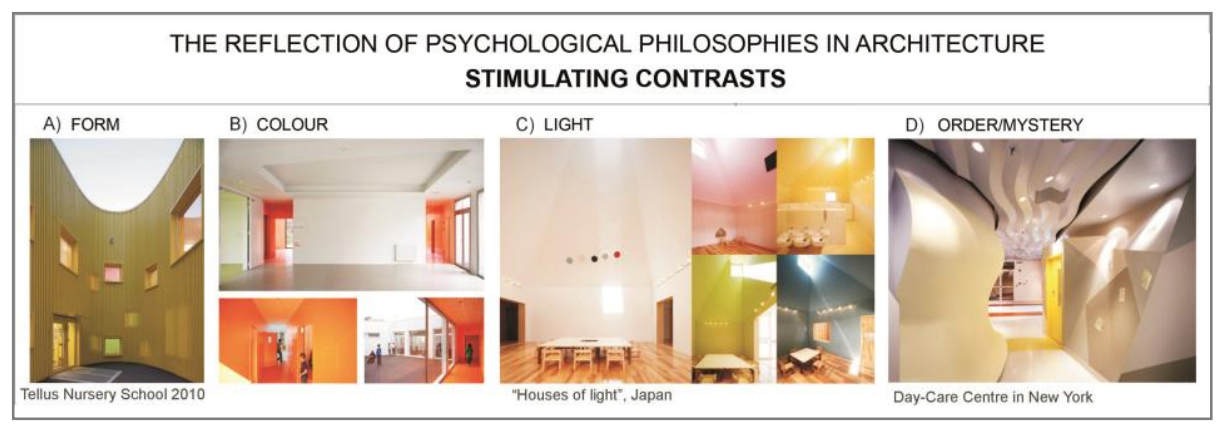

Fig. 3. Psychological studies of the contrasts.

\subsection{The perception of the building as an enormous space for games}

The next approach to the design of modern preschool institutions is the perception of the building form as a giant space for games. Currently, architects can pitch lots of ideas for children's play activities (Fig. 4).

Playful elements can be a part of the facade. The example is the reconstruction project of a kindergarten in Slovenia. The idea to turn the facade of the building in a playful element was influenced by the lack of equipment for games in the building. The new facade consists of turning bright boards, and children can change the exterior of the kindergarten and room lighting by themselves as well as study different colors and texture of materials (Fig. 4A).

The walking paths in the building can be turned into playful elements - atriums have trampolines and corridors, passages are organized like a climbing gym, stairs are duplicated with slides. For example, one kindergarten in Tokyo resembles a giant slide for children (Fig. 4b) $[4,7,8]$.

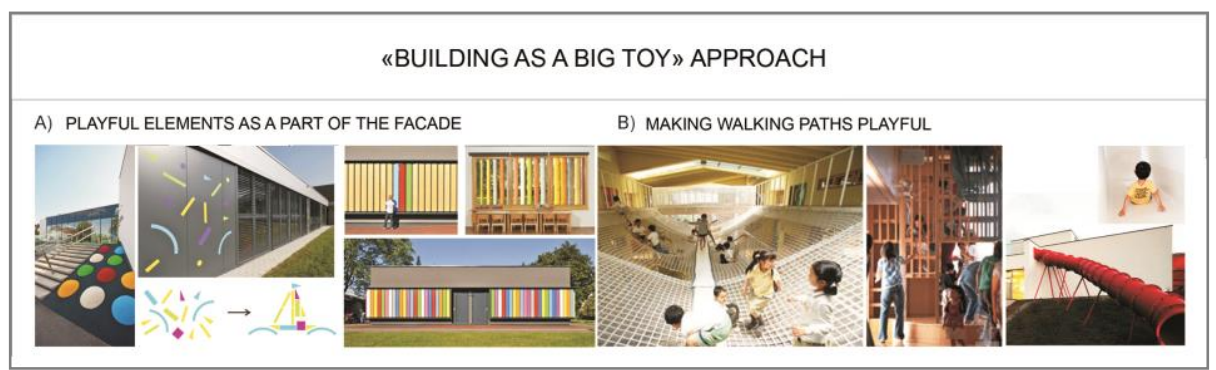

Fig. 4. The form of the building - a giant space for games.

\section{Modern approaches to the design of preschool institutions}

\subsection{The ecological approach to the design of preschool institutions}

Currently there also exists the ecological approach to kindergartens design implicating natural materials, organic combination of building and context, energy-efficient technologies (Fig. 5) [9].

The first example is the wooden extension to an existing kindergarten. The aim of the project was the organic combination with the context through form and material. The architects claimed that they were inspired by a metaphor from the book by A. de Saint- 
Exupery "the Little Prince" to create the form. All structural elements were made in advance, so the building was assembled during just 3 days (Fig. 5A).

In the building of the kindergarten in Austria, according to the architects' concept, the shading elements on the facade look like grass that helps you to perceive the building as if blending in the surrounding landscape. Additionally, architects believe that the green color has a positive effect on the psychological state of a child (Fig. 5b) [4].

The ring around the tree is a small extension to the existing kindergarten, including play rooms, outdoor classes and a bus stop (Fig. 5c) [4].

\subsection{Modular kindergartens}

Modular kindergartens are still a popular approach in the design of kindergartens. According to the architects of the modular project of a kindergarten in South America, the main task is to create a neutral space for children to give free play to their fancy.

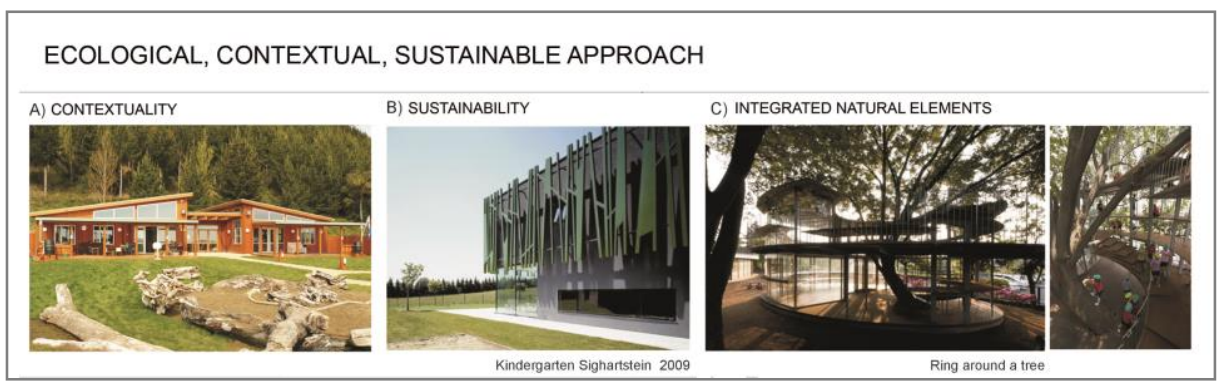

Fig. 5. The ecological approach to the design of kindergartens.

\section{Principles of preschool institutions design based on the psychological research}

Thus, on the basis of the above mentioned studies it was concluded that the environment an architect creates for children should educate and develop. By creating a comfortable environment for children of preschool age, an architect should follow the principles of:

- open structure room layout;

- allowing active movement in each room;

- allowing children to explore, develop sensory experience (the use of different texture surfaces);

- creation of private spaces for relaxation, quiet games and private lessons;

- $\quad$ ensuring visual diversity of forms and spaces, creation of contrasts;

- communication with the external environment, natural surroundings;

- creating the mood of the space by means of architecture, according to its function.

An example of the use of all above mentioned principles can be the kindergarten Kids Troplo in Hamburg (Germany), designed by the architectural firm Kadawittfeldarchitektur [10]. The facade of the building attracts attention by its interesting geometry, contrasting colors, bright color accents against a neutral background. Central, double-level space is a huge place for outdoor games with a wide variety of facilities for a child allowing to move and create. At the same time the architects took care of secluded spots, where tired children can have a rest, read or draw. The main staircase in the central space in addition to its initial function is an area for active play, movement and also may perform the role of the forum. Panoramic windows ensure good lighting and visual interrelation of the interior space with 
the natural environment. Moreover, the building of the kindergarten is not only functional and flexible for future changes, but also energy-efficient (Fig. 6).

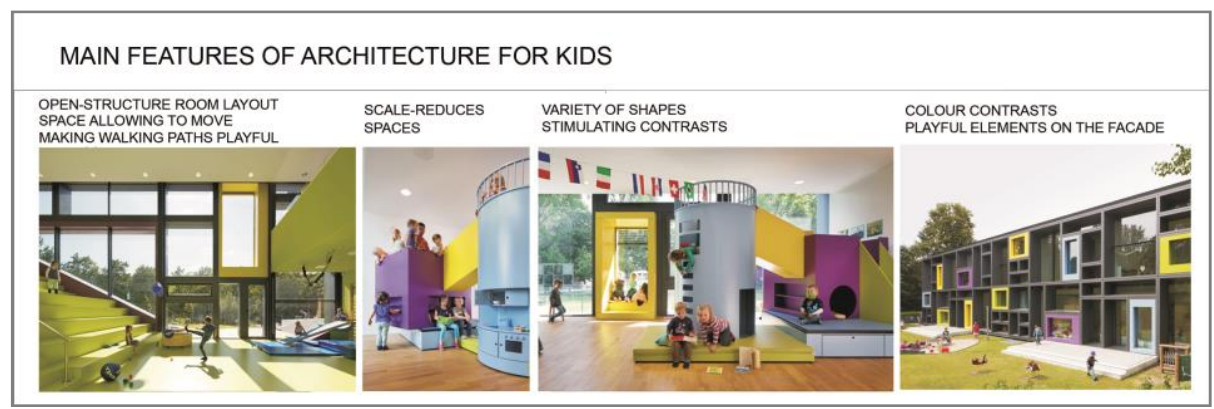

Fig. 6. The basic principles of preschool institutions design (the example of kindergarten Kids Troplo in Hamburg (Germany).

\section{Conclusions}

Recently in Russia, architects have also started looking for new and different from typical design approaches to organize children's educational institutions. The studies of the impact of social needs and psychology of children's perception on the architecture of a building and the organization of interior space have been conducted. Mostly, these studies are aimed at finding new principles of school buildings design [11, 12]. As for preschool institutions this question is less studied. This research can give a good start for a new step in the development of modern kindergartens in Russia.

\section{References}

1. architectureofearlychildhood.com

2. M. Dudek, Kindergarten Architecture: Space for Imagination (Routledge, USA, 2013)

3. M. Galindo, Kindergartens: Educational Spaces (Braun, 2011)

4. archdaily.com/category/kindergarten

5. Kids Spaces: Architecture for Children (Australia, 2004)

6. A.R. Olds, Child Care Design Guide, 1st edition

7. Magazine Speech: for children $\mathbf{1 4}$

8. dezeen.com/tag/kindergartens/

9. https://hqroom.ru/ekologychnyi-detskyi-sad-v-gamburge.html

10. https://hqroom.ru/detskyi-sad-troplo-kids-v-gamburge.html

11. S.V. Pozniak, Architectural-planning organization of a school building in the information-oriented society (the example of Samara), Candidate Degree Thesis in Architecture (Nizhny Novgorod, 2009)

12. V.Yu. Anisimov, Architecton: proceedings of higher education 34 (2011)

13. S. Ehmann, Learn for Life: New architecture for new learning (2012)

14. A. Ford, Designing the Sustainable School (Images Publishing, 2007)

15. http://citycelebrity.ru/citycelebrity/Post.aspx?PostId=74501 